\title{
Publisher's Note: Pairing in high-density neutron matter including short- and long-range correlations [Phys. Rev. C 94, 025802 (2016)]
}

D. Ding, A. Rios, H. Dussan, W. H. Dickhoff, S. J. Witte, A. Carbone, and A. Polls

(Received 23 August 2016; published 30 August 2016)

DOI: 10.1103/PhysRevC.94.029901

This paper was published online on 11 August 2016 with typographical errors on page 11 and 12. On page 11, left-hand column, the seventh line of the fourth paragraph should read as "of Fig. 11 we show density plots for the ${ }^{3} P_{2}\left({ }^{3} F_{2}\right)$ matrix..." On page 12, the labels in the right hand panels should read as " ${ }^{“ 3} F_{2} \ldots$. In the caption of Fig. 11, the last sentence should read as "(Right panels) The same for the ${ }^{3} F_{2}$ wave." The paper has been corrected as of 18 August 2016. The text, figure, and caption are correct in the printed version of the journal. 